Article

\title{
How to Optimize Ecosystem Services Based on a Bayesian Model: A Case Study of Jinghe River Basin
}

\author{
Chengyan Tang ${ }^{1}$, Jing $\mathrm{Li}^{1}{ }^{1}{ }^{*}$, Zixiang Zhou ${ }^{2}$, Li Zeng ${ }^{1}$, Cheng Zhang ${ }^{1}$ and Hui Ran ${ }^{1}$ \\ 1 School of Geography and Tourism, Shaanxi Normal University, Xi'an 710119, China \\ 2 College of Geomatics, Xi'an University of Science and Technology, Xi'an 710054, China \\ * Correspondence: lijing@snnu.edu.cn
}

Received: 14 June 2019; Accepted: 26 July 2019; Published: 1 August 2019

\begin{abstract}
Based on a Bayesian Network Model (BBN), we established an ecological service network system of the Jinghe River Basin in 2015. Our method consisted of using the distributed eco-hydrological model (Soil and Water Assessment Tool (SWAT) model) to simulate water yield, the Carnegie-Ames-Stanford Approach (CASA) model to estimate Net Primary Productivity (NPP), the Universal Soil Loss Equation (USLE) model to calculate soil erosion and the Crop Productivity (CP) model to simulate agricultural productivity to quantify the four ecosystem services. Based on the network established, the key variable subset and the visual optimal state subset, which we visualized, were analyzed and used to provide spatial optimization suggestions for the four kinds of ecosystem services studied. Our results indicate that water yield, concentrated in the middle and lower reaches of the mountain and river areas, is increasing in the Jinghe River Basin. NPP is continuously increasing and is distributed in the middle and lower reaches of the mountain areas on both sides of the river. Agricultural productivity also shows an upward trend, with areas of high productivity concentrated in the southern downstream mountain areas. On the contrary, the amount of soil erosion is declining, and the high erosion value is also declining, mainly in the upper reaches of the basin (in the Loess Hilly Area). Additionally, we found that a synergistic relationship exists between water yield, NPP and agricultural productivity, which can increase vegetation cover, leading to enhanced agricultural productivity. However, water yield can be reduced as required in order to balance the tradeoff between water yield and soil erosion. Clear regional differences exist in ecosystem services in the river basin. In the future, the two wings of the middle and lower reaches of the river basin will be the main areas of optimization, and it is likely that an optimal ecosystem services pattern can be reached.
\end{abstract}

Keywords: Bayesian network; optimization; interaction; spatial modeling; joint probability distribution

\section{Introduction}

Ecosystem services refer to all benefits obtained from an ecosystem, including direct and indirect gains [1]. Because these services are closely related to human life and survival, it is important to study their temporal and spatial changes under natural conditions, and in relation to the activities that humans have undertaken both for their survival and for the development of the earth [2-5]. In 2001, the United Nations implemented the Millennium Ecosystem Assessment International Cooperation Project, which proposed that ecosystem services should be divided into four categories: supply services, regulation services, support services and cultural services $[1,6]$. Complex interactions and feedbacks exist between the ecosystem services, which can be thought of as either synergies or trade-offs. The relationship between these services is crucial to the development and maintenance of ecosystems [7]. Recently, research on ecosystems has focused on the relationship between the 
supply and demand of ecosystem services, including spatial trade-off and optimization, ecological well-being and service flow [8-10]. With the development of different models and methods used in these investigations, there has been an increase in the number of studies on the spatial pattern of ecosystem services. Luisetti et al. [4] used a scenario analysis to study carbon storage and carbon emissions in marine habitats in the UK; Petitgas et al. [10] developed a marine ecological data system based on multi-table analysis to describe and detect spatial structures in ecosystems; Halouani et al. [11] employed OSMOSE models and Eco3M-Med Models to develop new indicators to assess the impact of fishing activity on marine ecosystems; Hong et al. [12] used wavelet power and coherence spectrum, coupled ecosystem functions and monsoon climates to explore both the carbon and water exchange in ecosystems under monsoon disturbances; Mao et al. [13] quantified the natural wetland-farm conversion to study the natural wetland and farmland space-time patterns under the influence of agricultural activities; Culhane et al. [14] evaluated the 'risk to ecosystem service supply' (RESS) of 99 aquatic ecosystems. Vörösmarty et al. [15] proposed ecosystem-based water security and sustainable development; Vallecillo et al. [16] applied environmental economic accounting system-test ecosystem accounting (SEEA-EEA) for 2012 nature recreational activities and developed ecosystem service accounts to measure changes in natural capital; Villarreal et al. [17] used the Ecosystem Functional Type (EFTS) method to evaluate whether vortex covariance sites are providing adequate representation, and used their combined core sites to address questions regarding decadal and inter-annual variability of ecosystem functional heterogeneity across the contiguous United States; Bernués et al. [18] studied the relationship between farmers and non-farmers on agriculture and the environment in high-value farmland, and explored the sustainability of farmland ecosystem services; Weitzman et al. [19] analyzed the status of aquaculture research in recent years, and in doing so, called attention to the application of the ecosystem services frameworks to promote sustainable development and recognized that aquaculture is closely related to ecosystems; Ron I et al. [20] used the Bayesian network to simulate ecosystem services and explored the applicability and flexibility of the model in ecosystem services; Hooper et al. [21] investigated how the sensitivity assessment can be applied to ecosystem services by considering the relationship between the sensitivity of the service and the sensitivity of the habitat in which it is supplied; Firbank et al. [22] explored how closed farm ecosystem services can meet the needs of humanity in the future; Leung et al. [23] proposed an ecosystem framework for the sustainable development of shared economic ecosystems; Danilo et al. [24] provided new insights into the experimental method for assessing the actual size of the ecosystem service by studying the resistance of bats to agro-ecosystems.

In light of the current status of ecosystems research, the Bayesian network has begun to be applied to ecosystem services, and optimization of the spatial pattern is in the exploratory stage. For example, the value of Bayesian networks in water quality and natural resource management was examined by Fox [25]; Landuyt et al. [26] used Bayesian networks to assess the opportunities and risks of integrated pond management. Macpherson et al. [27] used a Bayesian network model to analyze wetland protection decision making and management; Richards [28] applied this model to regional adaptation adjustment and early warning under climate change; while Stritih [5] used Bayesian networks to quantify uncertainties in ecosystem services assessment. Jung et al. [29] used Bayesian spatial regression models to analyze the relationship between urban structure and air pollution in Korea; Wu et al. [30] applied the Bayesian network and other methods to assess the fire risk at underground subway stations; Pérez-Sánchez et al. [31] used the Bayesian model to evaluate the hydrological model of water resources in the Spanish peninsula. In addition to these studies, Bayesian networks have also been widely used in fishing net construction, water purification, landscape protection and development, and food security [15,25,32-39]. The Bayesian network, first proposed by Pearl in 1986 is a large-scale data analysis tool that has the powerful ability to perform logical analysis as a neural network [40]. The powerful analysis of the Bayesian network has led to increased use of neural networks in research analysis in recent years [28]. This network, using a graphical modeling method, expresses the interaction between variables in the form of a network, and constructs a system 
probability model. The Bayesian network uses a directed acyclic graph composed of nodes representing random variables and directed edges connecting these nodes. Directed edges between nodes represent the relationship between these variables (from parent nodes to child nodes). Conditional probability is used to express the strength of the relationship and non-parent nodes use prior probability to express information [41-43]. Because this is a powerful tool for probabilistic reasoning and uncertainty analysis, this method is widely used in modeling and resource management decision making. It has previously been applied in medicine, biology, machine learning, as well as other fields, and it has gradually expanded to the study of ecosystem services [44,45].

Many groups have worked to study the ecological and environmental systems at work in the Jinghe River Basin, Chen et al. [46] used principal component analysis and correlation analysis to analyze Normalized Difference Vegetation Index (NDVI) and precipitation in the Jinghe River Basin, and found that the dynamic change of vegetation is closely related to climate change, flood and human activities; Gao-di et al. [47] analyzed precipitation-landscape-runoff changes and interactions; Guo et al. [48] used the sliding partial correlation coefficient method to analyze the variation of rainfall and runoff relationships, and used the double cumulative curve method to verify their analysis; Juan et al. [49] used the SWAT model to simulate the hydrological process in the Jinghe River Basin, and embedded a terrace module inside of SWAT model to simulate river runoff. Under the Budyko framework, Zhi et al. [50] explored the effects of rainfall and evapotranspiration on the temporal and spatial variation of runoff at sub-basin scales; Peng et al. [51] analyzed the impact of water and soil conservation in the basin by using the distributed hydrological model SWIM, and the vegetation ecosystem model BIOME; Suo et al. [52] investigated the relationship between the vegetation landscape pattern and runoff dynamics, and explored the relationship between landscape characteristics and runoff in the Jinghe River Basin; Yang et al. [53] studied the watershed water demand and analyzed the grain size effect of the landscape index. Zhen et al. [54] analyzed the severity of the Jinghe River Basin problem through problem matrix and problem tree analysis. They determined that the order of contributing factors from high impact to low impact is as follows: soil erosion, low land productivity, natural disasters, vegetation damage, etc. Pan et al. [55] conducted research on ecosystem services in the Jinghe River Basin, but it is still in the evaluation and quantification stage.

Therefore, it is particularly important to analyze and optimize the spatial pattern of ecosystem services in the Jinghe River Basin. Our work uses the Bayesian network to analyze the ecological system service spatial pattern of the study area with probability theory, based on the analysis of the trade-offs and synergies between the four ecosystem services of water yield, NPP, crop production and soil erosion in the study area, We explored the following two questions: is it feasible to establish ecosystem services network in the Jinghe River Basin using the Bayesian network model and, if so, can it be used to optimize the spatial pattern of the river basin and provide development strategies for the ecological development of the Jinghe River Basin.

\section{Data and Methods}

\subsection{Study Area}

The Jinghe River is the first tributary of the Weihe River, which is the largest tributary of the Yellow River. This river originates in the eastern foot of the Liupan Mountain in Ningxia. The basin has a watershed area of $45,421 \mathrm{~km}^{2}$ and is located in the middle of the Loess Plateau, between Liupan Mountain and Ziwuling Mountain $\left(106^{\circ} 20^{\prime}-108^{\circ} 48^{\prime} \mathrm{E}, 34^{\circ} 24^{\prime}-37^{\circ} 20^{\prime} \mathrm{N}\right)$. The annual average temperature of the study area is $8^{\circ} \mathrm{C}$ and the annual precipitation is $350-650 \mathrm{~mm}$, with higher rainfall occurring mainly in the summer. The terrain is higher in the northwest and lower in the southeast, with an elevation range of 416-2908 m [56]. The study area can be divided into the northern Loess Hilly area, the central Loess residual area, the southwest mountain forest area and the southeast mountain river area, as shown in Figure 1. 

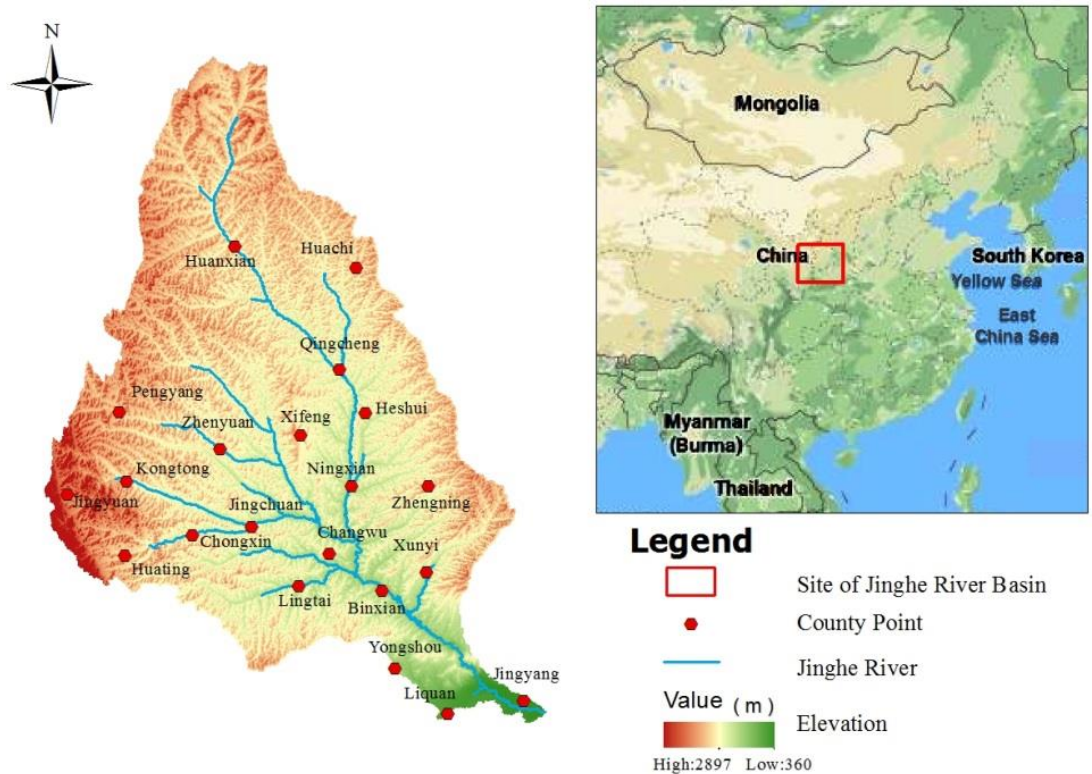

Figure 1. Administrative map of study area.

\subsection{Sources of Data}

Data used in this paper include basic geographic information data on the Jinghe River Basin, including information about the administrative region, county, river, road, elevation, land-use type and soil type. This information was obtained from the National Basic Information Center; as well as from land-use data from 2000, 2005, 2010 and 2015. Meteorological data from 2000 to 2015 is also included (comprising data (Temperature, precipitation, radiation and other data) from 17 meteorological stations including Huajialing, Zhongning, Yanchi, Dingbian and Wuqi stations) and was derived from the China Meteorological Data Network. NDVI and evapotranspiration data is from NASA.

\subsection{Ecosystem Services Models}

\subsubsection{Water Yield Simulation}

Water yield was determined from simulations based on the SWAT model, which uses the water yield equilibrium equation. Equation (1) [57]:

$$
S W_{t}=S W_{0}+\sum_{i=1}^{t}\left(R_{\text {day }}-Q_{\text {surf }}-E_{a}-w_{\text {seep }}-Q_{g w}\right)
$$

where $S W_{t}$ is final soil water content; $S W_{0}$ is initial soil water content; $\mathrm{t}$ is the number of days; $R_{\text {day }}$ is precipitation; $Q_{\text {surf }}$ is surface runoff; $E_{a}$ is evapotranspiration; $w_{\text {seep }}$ is the amount of water entering the aeration zone through the soil profile; and $Q_{g w}$ is regression flow. Except for $S W_{t}$, all variables were measured on day $i$.

\subsubsection{NPP Estimation}

The CASA model was used to calculate the net primary productivity (NPP) of vegetation [58]. This model uses two factors to determine NPP: photosynthetic active radiation (APAR) and actual light energy utilization $(\varepsilon)$ :

$$
N P P(x, t)=\operatorname{APAR}(x, t) \times \varepsilon(x, t)
$$

$\operatorname{APAR}(x, t)$ denotes photosynthetic effective radiation absorbed by pixel $x$ in month $t\left(\mathrm{~g} \mathrm{C} \mathrm{m}^{-2} m o n t h^{-1}\right)$; and $\varepsilon$ is the actual light utilization rate of pixel $x$ in month $t\left(\mathrm{gCMJ}{ }^{-1}\right)$. 


\subsubsection{Crop Productivity Calculation}

The equation from the model of crop productivity was used [59]:

$$
C P=P_{V} \times I_{z r d}
$$

where $P_{V}$ represents the climatic productivity of crops; and $I_{z r d}$ is the level of land use, determined by the classification of agricultural land in China. $P_{v}$ is calculated as shown below, where $V$ is average annual evapotranspiration.

$$
P_{V}=30000\left(1-e^{-0.000956(V-20)}\right)
$$

\subsubsection{Estimation of Soil Erosion}

The Universal Soil Loss Equation (USLE) was used to calculate the amount of soil erosion [60]. This equation is based on multiple theories and statistical analysis of field observation data and takes into account multiple different factors. The USLE is expressed as:

$$
A=R \times K \times L \times S \times P \times C
$$

where $A$ is the amount of soil erosion; $K$ is the soil erodibility factor; $R$ is the rainfall erosivity factor; $K$ is the factor; $L$ and $S$ are the slope length factor and slope factor, respectively; $P$ accounts for soil and water conservation measures; and $C$ represents the surface vegetation cover and management factor.

The $R$ value used in Equation (5) was calculated using the following equation [61]:

$$
R=\frac{105.44 \times P_{1}^{1.2}}{P}-140.96
$$

where $P_{1}$ is the sum of precipitation from June to September; and $P$ is annual precipitation.

The $K$ value was calculated based on the universal equation of Wischmeier [60]:

$$
K=\left[2.1 \times 10^{-4}(12-a) M^{1.14}+3.25(b-2)+2.5(c-3)\right] / 100
$$

In this equation, $M$ is the particle size parameter, calculated as [(percentage of silt and ultra-fine sand $) \times(100$ - percentage of clay $)] ; a$ is the organic matter fraction; $b$ is the number of soil structures; and $c$ is the profile permeability grade.

The following equation was used to calculate the slope length factor, $L$, [60]:

$$
L=(\lambda / 22.13)^{m}
$$

where 22.13 is the slope length of the standard plot; $\lambda$ is slope length (obtained using DEM); and $m$ is the slope length index, calculated according to the following criteria: $m=0.2(\theta<1 \%)$; $m=0.3(1 \% \leq \theta<3 \%) ; m=0.4(3 \% \leq \theta<5 \%) ; m=0.5(\theta>5 \%)$.

The slope factor, $S$, was calculated by combining McCoold's gentle slope calculation and steep slope calculation equations, as shown below [62]:

$$
S=\left\{\begin{array}{c}
10.8 \sin \theta+0.03(\theta<5 \%) \\
16.8 \sin \theta-0.50(5 \% \leq \theta<10 \%) \\
21.9 \sin \theta-0.96(\theta \geq 10 \%))
\end{array}\right.
$$

where $S$ is the slope factor; and $\theta$ is the gradient.

The $P$ value reflects soil and water conservation measures, indicating the ratio of soil lost after special measures to the amount lost when planting along the slope. In our study, we refer to previous studies to determine the general $P$ value for different types of land use [63]. 
Estimation of the $C$ value was performed using surface vegetation cover and management factors, which account for the amount of soil loss on farmland under certain conditions compared to that on continuous fallow land under the same conditions. The equation used is shown below [64]:

$$
C=\left\{\begin{array}{c}
1(F=0) \\
0.6508-0.3436 \lg F(0<F \leq 78.3 \%) \\
0(F>78.3 \%)
\end{array}\right.
$$

In this equation $F$ is vegetation coverage, which is calculated using the following equation [64]:

$$
F=108.49 I+0.717
$$

where $I$ is the normalized vegetation index.

\subsection{Spatial Pattern Optimization of Ecosystem Services Based on BBNs}

\subsubsection{Bayesian Network Model}

The Bayesian network, also known as a reliability network, is an extension of Bayes' method and one of the most effective theoretical models in the field of uncertain knowledge representation and reasoning [32]. Since the method was proposed by Pearl in 1988, it has become a significant area of research in recent years. A Bayesian network is a Directed Acyclic Graph (DAG), consisting of nodes representing random variables connected by directed edges representing the relationship between the parent and child nodes [65]. The strength of the relationship is expressed using conditional probability, and prior probability is used to express information without a parent node [66].

The conditional probability table expresses the strength of the relationship between parent node, $X$, and child node, $Y$. Each row in the table consists of the state combination of the parent node and conditional probability $p\left(Y_{i} \mid X_{i}\right)$, that is, the probability of the occurrence of each $Y$, where $Y_{i}$ represents concrete state of the child node, when the discrete state $X_{i}$ of parent node $X$ occurs. The conditional probability table can be obtained not only from expert knowledge, but also from actual observational data. The probability distribution of the child node is determined by the probability distribution and conditional probability of the parent node. For a node without a parent node, its probability distribution is determined from a prior probability distribution $p(X)$. The joint probabilities of all variables in Bayesian networks can be obtained from conditional probability distribution multiplication of all nodes, enabling Bayesian networks to effectively calculate the probabilistic distribution of any node in the network. This provides a theoretical basis for optimizing service patterns according to the probabilities of four ecosystem service nodes $[67,68]$.

$$
p\left(X_{1}, X_{2}, \cdots, X_{n}\right)=\prod_{i=1}^{n} p\left(X_{i} \mid \text { parents }\left(X_{i}\right)\right)
$$

Based on the quantitative methods of ecosystem services, the relevant impact factors were selected as nodes, and the Bayesian conceptual network of ecosystem services was constructed, as shown in Figure 2. The grid layers corresponding to nodes were discretized using ArcGIS software. According to the actual distribution of variables in the study area, the selected grid data of each variable was divided into four levels: low, medium, high and highest, designated as 1, 2, 3 and 4, respectively. For example, "evapotranspiration $=3$ " means high evapotranspiration, which corresponds to $5362-9827 \mathrm{~mm}$. Specific classification criteria for all factors are shown in Table S1 (Supplementary Materials). Evapotranspiration data were derived from $250 \mathrm{~m}$ spatial resolution MODIS data in 2015, watershed water yield data were calculated using the SWAT model, and NPP data of vegetation, crop production and soil erosion data were determined using the calculation methods described above. By extracting the value of the discrete raster data layer into a single raster data layer and inputting 
its attribute table into the Bayesian network model, we obtained the probability distribution of all nodes in the ecosystem services Bayesian network of the Jinghe River Basin in 2015. Based on this, the conditional probability table of each node in the network was calculated using the conditional probability formula:

$$
P(B \mid A)=P(A B) / P(A)
$$

where, $P(A B)$ is the probability of two events $A$ and $B$ occurring together; $P(A)$ is the probability of event $A$; and $P(B)$ is the probability of event $B$.

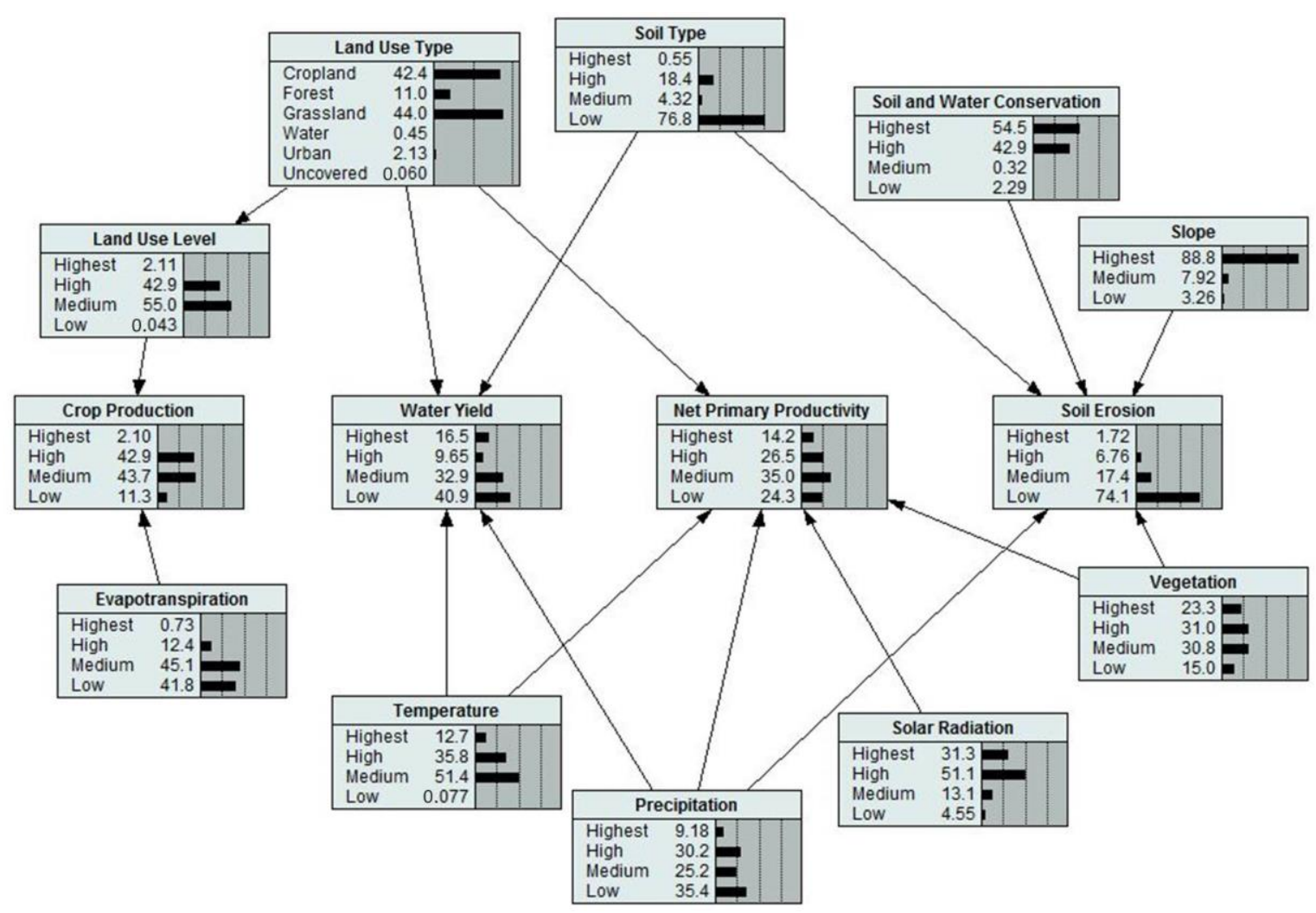

Figure 2. Bayesian belief network construction for ecosystem service.

\subsubsection{Optimization of Ecosystem Service Pattern}

We constructed a Bayesian network model of ecosystem services in the Jinghe River Basin, and the key state subset of key variables was determined using a conditional probability table and sensitivity analysis. The subset space was visualized using ArcGIS software [20]. And the region where the key state subset of key variables corresponding to different levels of the four ecosystem services functions occurring simultaneously was drawn. The determination of the key state subset of key variables involved determining the key variables and the key state of each key variable.

By running the Bayesian network model, we were able to determine the probability of each node state and the joint probability of two or more node state combinations. Based on this, the conditional probability between each impact factor and each ecosystem service was calculated. The state with the highest conditional probability for the impact factor was selected as the key state of the variable when the service levels were at the highest, high, middle and low states. The factor state sets corresponding to these service levels are called 'subsets of key state of variables I, II, III and IV'. The higher the level, the higher the probability of the service capability occurring in the corresponding subset area. In order to evaluate the relative importance of Bayesian network nodes, we used Netica software to perform sensitivity analysis, which evaluates whether a service node is sensitive to changes in other impact factors. 
After determining the subset of the key state of key variables of ecosystem services, the scenario with the largest ratio of subset I area to total research area was selected as the scenario of optimal service which can be optimized. The subset I of key variables in this scenario was identified as the optimal subset of state, and the optimal region was divided according to the optimal subset of state. The specific process is shown in Figure 3.

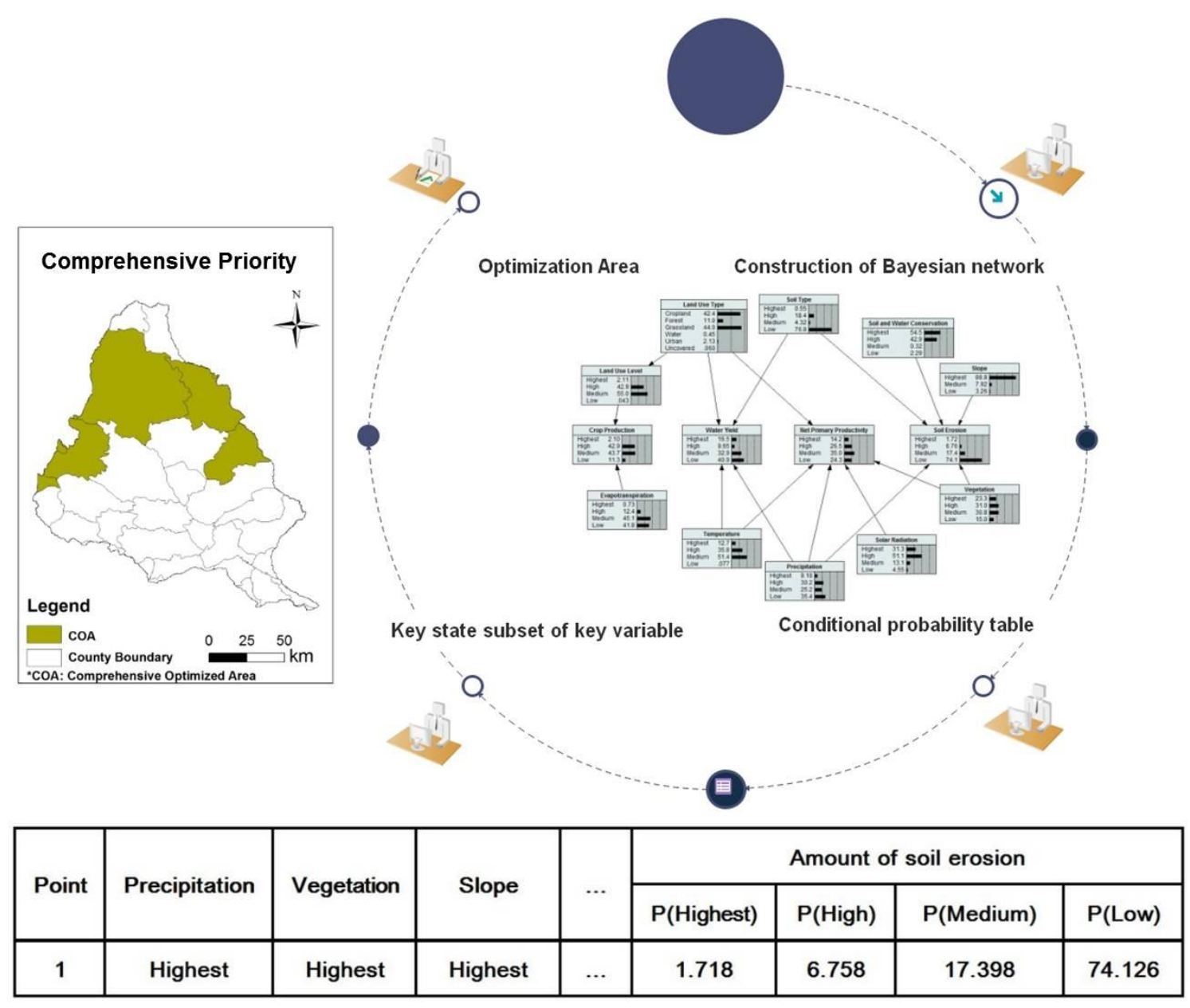

Figure 3. Optimization principle of ecosystem service.

\section{Results}

\subsection{Validation of SWAT Water Yield}

A SWAT model was used to simulate water yield in the Jinghe River Basin [69]. To ensure our results were consistent with others in the field, our model results were calibrated and validated. Due to the limitation of available measured data, we used data from 2004 to 2009 as calibration data and measured data (2010 to 2015) as validation data. We also combined simulated water yield data (2004 to 2015) with the SWAT-CUP software to calibrate and validate our results. Using SWAT-CUP, we obtained the optimal set of parameters in Table S2 (Supplementary Materials) and the simulation results, as well as the correlation coefficient $\left(R^{2}\right)$ and Nash Sutcliffe efficiency (NSE). The $R^{2}(0.66)$ and NSE (0.59) of the rate periodic simulation indicate that the SWAT simulation results were in line with the actual watershed, as shown in Figure 4. NSE is Nash-Sutcliffe efficiency, which is generally used to verify the quality of hydrological model simulation results. The value can range from negative infinity to 1 , with values closer to 1 representing a more accurate simulation. The simulation correlation coefficient $\left(\mathrm{R}^{2}=0.69\right)$ during the validation period also indicated that SWAT results were credible, as shown in Figure 5. In 2010, due to frequent rainstorms, the peak flow was relatively high, which 
could affect our simulation as the model is affected by the weather, land use, soil and other data. There is a large deviation, but overall, our model is accurate and credible.

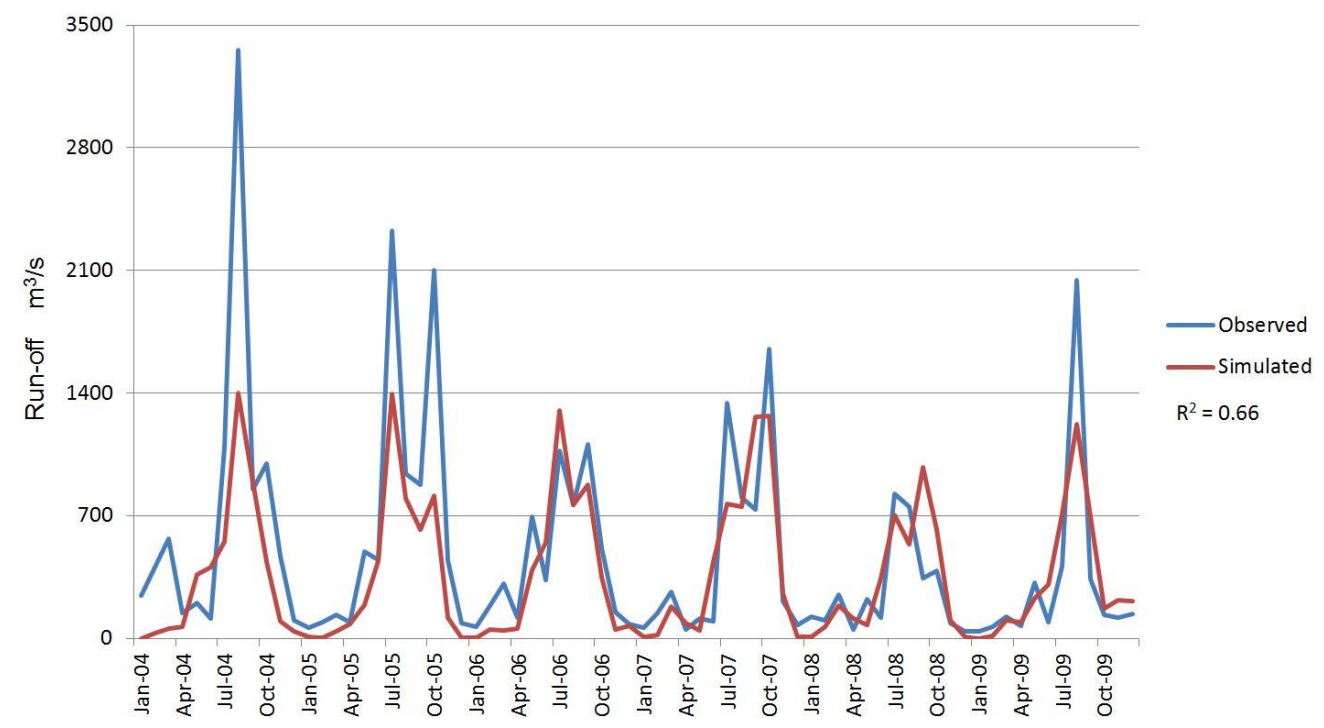

Figure 4. Simulated and realistic monthly runoff data in validation period from 2004 to 2009.

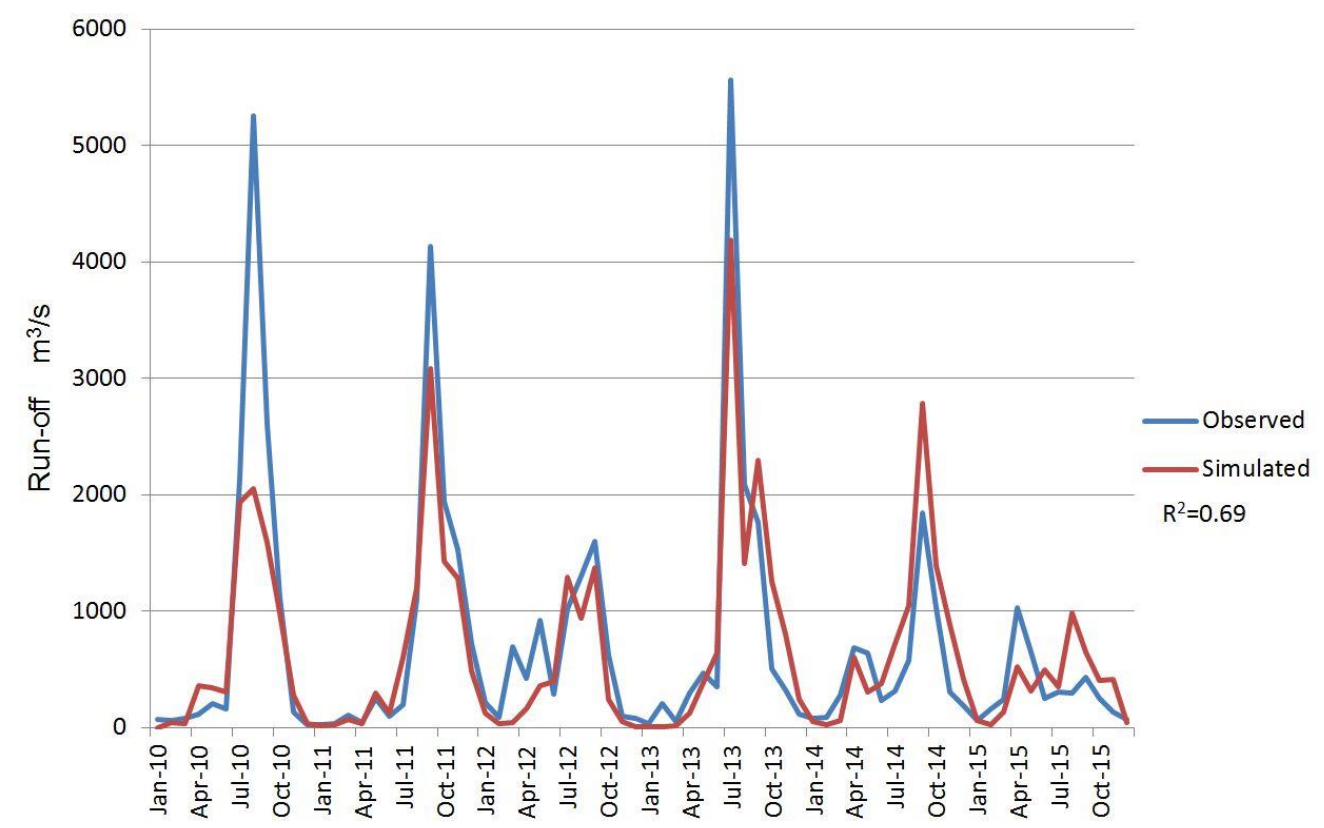

Figure 5. Simulated and realistic monthly runoff data in validation period from 2010 to 2015.

\subsection{Ecosystem Services}

We analyzed four ecosystem services in 2000, 2005, 2010 and 2015, and our observations are described below. Water yield in the basin recorded an upward trend, and it is concentrated in the southern part of the middle reaches, the eastern mountain and river areas of the lower reaches. In 2000, water yield was $24.62 \times 10^{6} \mathrm{~mm}$ and was concentrated in Ningxian County, Zhengning County, Gansu Province, Xunyi County and Shaanxi Province. By 2015, it had increased to $34.61 \times 10^{6} \mathrm{~mm}$ and had expanded to cover the entire downstream area, including Jingchuan, Chongxin and Lingtai counties in Gansu Province, Longxian, Binxian and Fengxiang counties in Shaanxi Province. In addition, the water yield distribution area (previously recording a low value) also increased, particularly in downstream Chunhua County, Liquan County and Jingyang County, which have transformed into areas with a high water yield. 
The vegetation NPP also increased significantly, from $430.03 \mathrm{t} / \mathrm{ha}$ in 2000 to $855.56 \mathrm{t} / \mathrm{ha}$ in 2015 . NPP was mainly distributed in the middle and lower reaches of the mountain areas. The main areas of NPP distribution change were also concentrated in the mountainous areas on both sides of the river, spreading from both sides to the interior. In 2000, NPP was mainly distributed in Ningxian, Zhengning, Xunyi and Heshui, as well as in the Longxian, Linyou and Qianyang counties in the eastern and western mountainous areas, respectively. From 2000 to 2015, the density of NPP increased in the centralized distribution area and spread to the central area of the river basin, covering Changwu County, Bin County, Chunhua County, Yongshou County, Liquan County, Pingliang City and Jingchuan County, as shown in Figure 6.
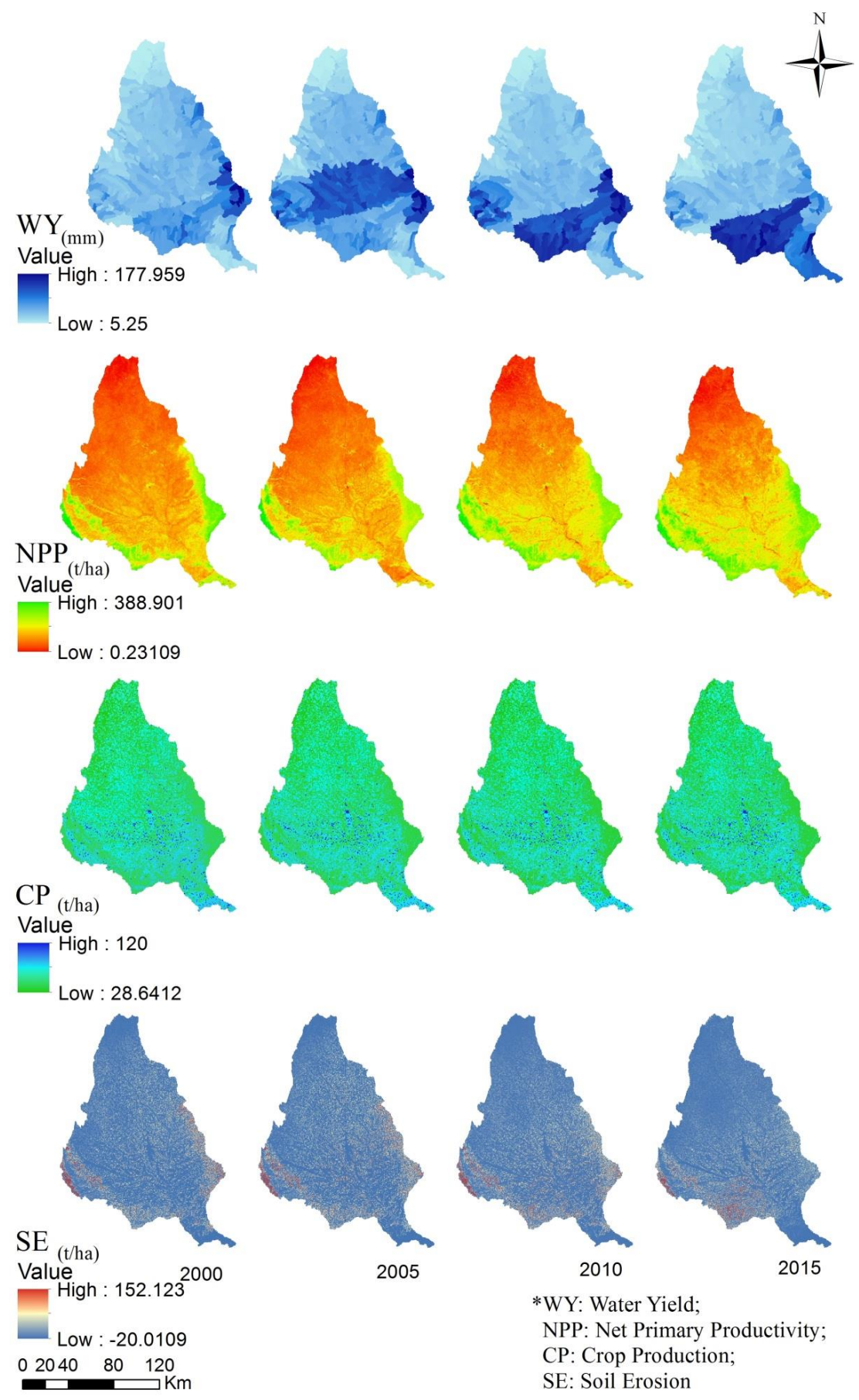

*WY: Water Yield;

NPP: Net Primary Productivity; CP: Crop Production; SE: Soil Erosion

Figure 6. The change and distribution of ecosystem services in Jinghe River Basin in 2000, 2005, 2010, 2015. 
Crop production increased from $280.94 \times 10^{4} \mathrm{t} / \mathrm{ha}$ in 2000 to $291.47 \times 10^{4} \mathrm{t} / \mathrm{ha}$ in 2015 . Although the main distribution areas did not change significantly, the area of high value crop production generally increased, leading to an overall increase in crop production. The distribution areas were mainly concentrated in Changwu County, Chunhua County, Liquan County and Jingyang County of Shaanxi Province, Zhenyuan County, Ningxian County, Jingchuan County, Huating County, Lingtai County, Xifeng City, Pingliang City and Jingyuan County of Gansu Province.

Contrary to the three ecological services already noted, spatial and temporal distribution of soil erosion displayed a downward trend, decreasing from $12.76 \times 10^{3} \mathrm{t} / \mathrm{ha}$ in 2000 to $2.07 \times 10^{3} \mathrm{t} / \mathrm{ha}$ in 2015 . Soil erosion mainly occurred in the Loess Hilly Area in the upper reaches of the basin. In 2000, soil erosion was concentrated in the mountainous areas on the southern side of the basin, and in Heshui County, Ningxian County, Zhengning County, Zhuanglang County, Huating County, Pingliang City, Guyuan County, Longde County and Jingyuan County in Ningxia, and Jingyang County downstream. By 2015, Pingliang City, Guyuan County and Jingyuan County in the West wing were still recording high levels of soil erosion, however erosion declined in Heshui County and Ningxian County in the East Wing mountain area. In addition, Changwu County, Linyou County, Qianyang County, Fengxiang County, Jingchuan County and Lingtai County in Gansu Province recorded significant increases in soil erosion.

\subsection{Spatial Pattern Optimization of Ecosystem Services}

Based on probability theory, the Bayesian network model obtained the optimal state subset of key variables in the study area and screened out the regions that need to be optimized. The selected areas can be optimized for development, which can effectively improve the quality of ecosystem services in the area studied. According to Tables S3a-d (Supplementary Materials), soil was identified as the most critical factor for water yield in the Jinghe River Basin, with temperature, land-use type and precipitation being the next most important factors, as shown in Table S3a. Effective soil management in the upper and middle reaches provided the most powerful improvement of regional water yield services. The key factors affecting NPP were vegetation, precipitation and radiation, with vegetation as the highest probability factor, as shown in Table S3b. Therefore, in Pengyang County and Huachi County, Guyuan County, central and southern Huanxian County, southern Wuqi County in the east and northern Heshui County, improving vegetation coverage will have the greatest effect on enhancing NPP in the basin. Evapotranspiration and land-use level were the key factors affecting crop production services, as shown in Table S3c. When evapotranspiration and land-use levels were both high, the most effective way to rapidly improve crop production capacity in the study area was achieved by optimizing the middle and lower reaches of the river basin. The key factors affecting soil erosion were precipitation, slope, $\mathrm{P}$ (the factor of soil and water conservation measures), vegetation and soil type, with precipitation probability being the most important factor, as shown in Table S3d. This subset was mainly distributed in Pengyang and Huachi counties, northern Qingyang and Zhenyuan counties, and southern Huanxian counties. Soil erosion in these regions improved and the optimization effect was remarkable.

Using a broad analysis of the various factors, we can obtain comprehensive optimization zones. Figure 7 indicates that soil improvement in Wuqi County of Shaanxi Province, Huanxian County, Huachi County, and Heshui County of Gansu Province, as well as in Guyuan County and Pengyang County of Ningxia, can consolidate soil and reduce soil erosion by promoting vegetation growth. This is also true for Huanxian County, Huachi County and Pengyang County, where the soil can be developed to improve agricultural practices and increase crop production, as shown in Figure 7. 


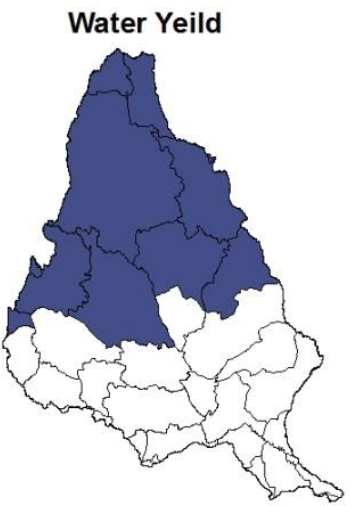

Soil Erosion

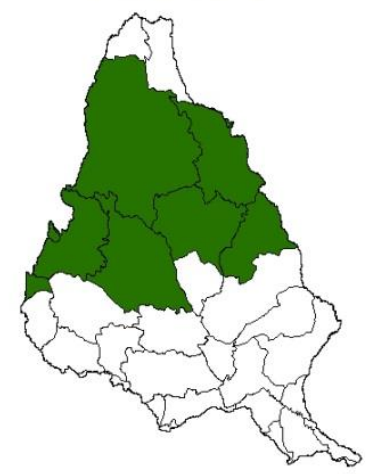

Net Primary Productivity

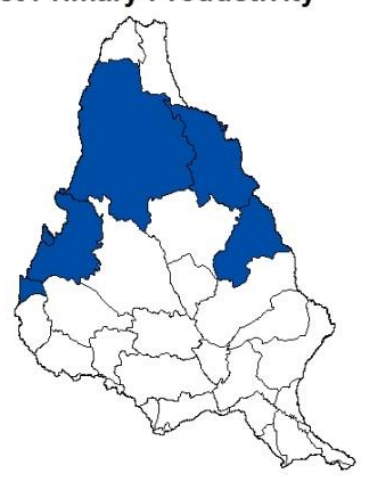

Comprehensive Priority

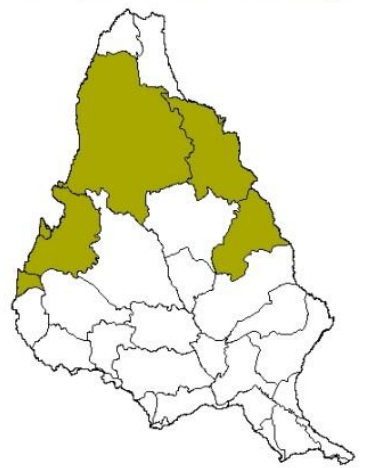

Crop Production
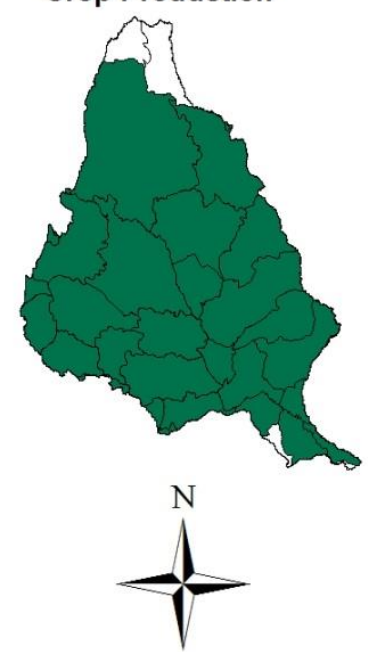

Legend

WY Conservation Optimized Area

NPP Conservation Optimized Area

CP Conservation Optimized Area

SE Conservation Optimized Area

Comprehensive Optimized Area

County Boundary

$87.5 \quad 175$

*WY: Water Yield; NPP: Net Primary Productivity; CP: Crop Production; SE: Soil Erosion.

Figure 7. Key state subset distribution of key variables.

\section{Discussion}

\subsection{The Relationship of Trade-Offs Between Ecosystem Services}

Based on our results, it is clear that all the optimization areas are concentrated in the Loess Plateau and the mountainous areas in the northern part of the Jinghe River Basin. The key factors restricting the development of these areas are soil, vegetation and precipitation, and the impact of these factors on the four ecosystem services cannot be ignored. Therefore, we further analyzed the relationship between ecosystem services in regards to the temporal and spatial changes in these services, and also researched the internal and external forces at work in the formation of these services. We used $\mathrm{R}$ to analyze the correlation between the four ecosystem services in Figure 8.

Figure 8 shows the correlation, ranging from -1 to 1 , between water yield, NPP, agricultural production and soil erosion in our study. Blue and red indicate positive and negative correlation, respectively. The darker the color, the stronger the correlation, and the closer the absolute value is to 1. Conversely, the lower the correlation is, the closer to the absolute value will be to 0 . Overall, it is clear from our results that the interaction between ecosystem services has a significant impact on the development and optimization of watershed ecological patterns. Our analysis of water yield, crop production, NPP and soil erosion in the Jinghe River Basin indicate that trade-offs and synergies exist between these ecosystem services, as shown in Figure 8. There is a synergistic relationship between water yield, NPP and agricultural production, and the degree of synergy with NPP is greater than the synergy with agricultural production services. There is also a cooperative relationship between NPP and agricultural production services, which is the weakest of all the synergistic relationships. The relationship between soil erosion and water yield, NPP, and agricultural production service shows trade-offs. The relationship between soil erosion and NPP is the strongest, followed by water yield and agricultural production services. Therefore, when undertaking actual ecological environment optimization, the improvement of one of the ecosystem services will also change the other ecosystem 
services, positively or negatively. Planting trees and undertaking other greening environmental measures are bound to significantly enhance the vegetation NPP and water conservation ecosystem services and reduce the amount of soil erosion. However, due to the relatively weak synergy between NPP and agricultural production, the effect of changes in vegetation types, such as changes in forestation and crops, on agricultural production must also be taken into account. For the specific optimization of the river basin ecological service system, we must selectively control the influencing factors according to the development needs. For example, in order to promote agricultural development, it is necessary to improve the soil types, change the type of vegetation through planting and other technologies, increase the conversion of bare land and wasteland to cultivated land and grassland, and protect the development of existing cultivated land. These measures will inevitably lead to changes in the types of land use, as well as lead to an increase in soil retention capacity and NPP and a decrease in erosion. In complex ecosystems, these changes are inextricably linked to each other.

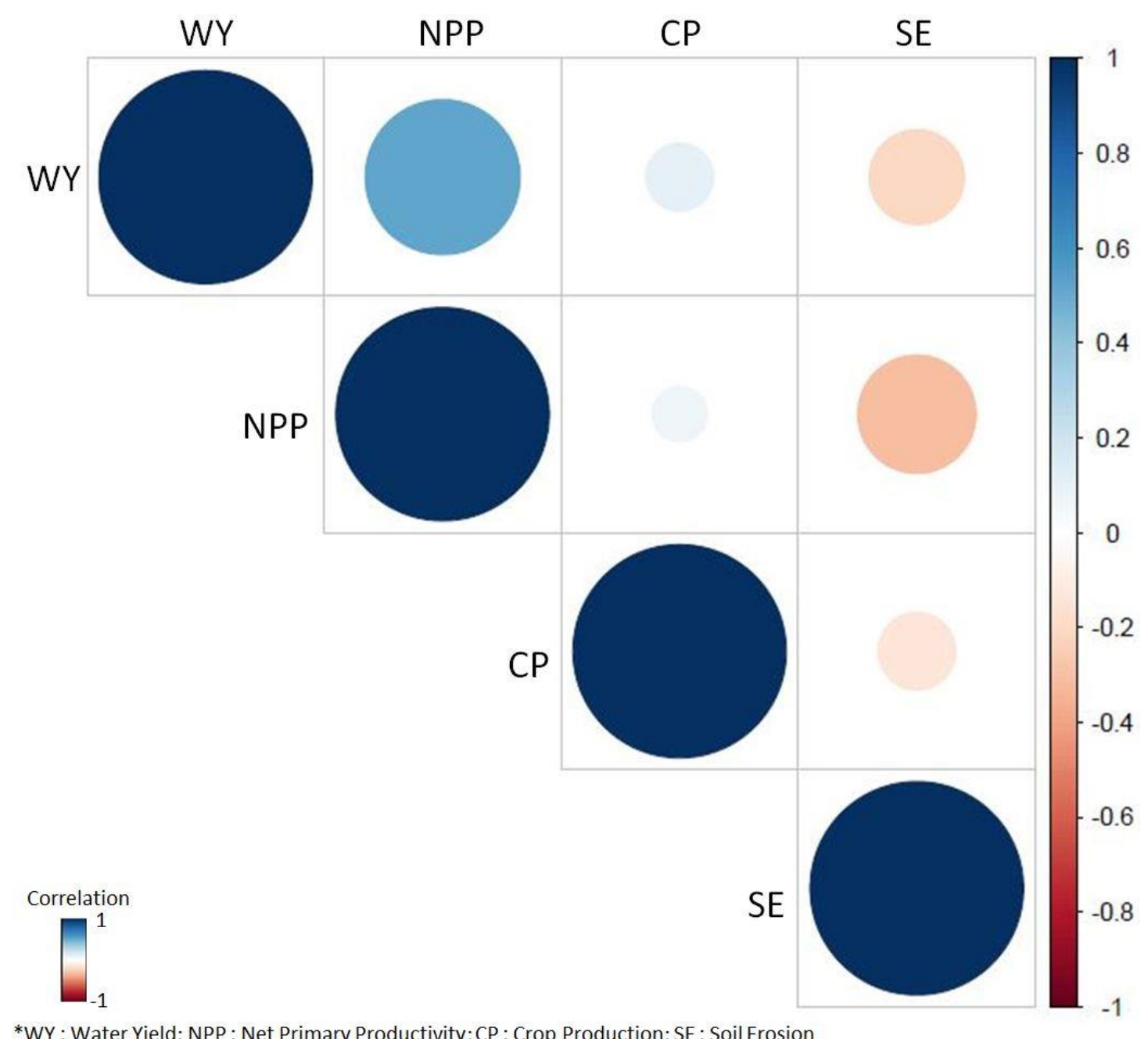

*WY : Water Yield; NPP : Net Primary Productivity; CP : Crop Production; SE : Soil Erosion

Figure 8. Relationship of trade-offs between Water Yield, Net Primary Productivity, Crop Production and Soil Erosion.

\subsection{Bayesian Network Model}

As a graphical modeling tool, the Bayesian network uses probability tables to represent causality among variables. Its powerful application value lies in its ability to analyze the relationships and associations behind the data. It uses the existing data and combines prior knowledge to construct a Bayesian network model. Expert system knowledge is no longer the basis for building a network structure $[68,69]$. Because of this, data preparation and selection are very important factors that affect 
the model. This paper quantifies four kinds of ecosystem services based on a number of methods and principles related to water yield, NPP, crop production and soil erosion in river basins, and then chooses the influencing factors affecting the comprehensive development of ecosystem services, taking into account both natural factors and human land use activities. Our work uses GIS tools to process data and establishes a more complete ecosystem service network. A Bayesian network of these ecosystem services was constructed in order to explore the trade-offs and synergies between services, analyze the comprehensive effects of multiple factors, including natural and human influences, on ecosystem services, and optimize the spatial pattern of ecosystem services. The Bayesian network model has become a flexible, comprehensive and powerful tool for ecosystem services, as it is able to provide reliable data support for regional planning.

\section{Conclusions}

In this study we quantified the water yield service, soil erosion, agricultural productivity and NPP of the Jinghe River Basin ecosystem using SWAT and CASA, in addition to other models and methods. Based on probability theory and the Bayesian network model, we constructed an ecosystem service network model of the basin and studied the relationship between factors and services. The spatial pattern optimization of ecosystem services in the river basin was also analyzed. Our results show that:

(1) Watershed water yield is positively correlated with vegetation NPP and agricultural productivity, as both NPP and agricultural productivity increased with increasing water yield. However, water yield is negatively correlated with soil erosion. In our research, the optimal areas of the four ecosystem services in Jinghe River Basin are mainly located in the middle reaches.

(2) The Bayesain network model is a powerful neural network tool that can be used to simulate an ecosystem service network and has an important place in ecosystem service research. It can be used to guide the optimization of the spatial pattern of ecosystem services and provide policy support for watershed development.

Supplementary Materials: The following are available online at http://www.mdpi.com/2071-1050/11/15/4149/s1, Figure S1: Bayesian Network, Table S1: State classification of factors, Table S2: Analysis result of sensitivity parameter, Table S3a: The hierarchy of factors based on BBNs of Water Yield, Table S3b: The hierarchy of factors based on BBNs of Net Primary Productivity, Table S3c: The hierarchy of factors based on BBNs of Crop Production, Table S3d: The hierarchy of factors based on BBNs of Soil Erosion, Table A: State classification of factors, Table B: the hierarchy of factors based on BBNs of Soil Erosion (\%).

Author Contributions: Conceptualization and methodology, C.T. and J.L.; software, L.Z. and J.L.; validation, C.T., C.Z. and H.R.; formal analysis and investigation, resources, data curation, writing-original draft preparation and visualization, C.T.; writing - review and editing, C.T. and J.L.; supervision, J.L.; project administration and funding acquisition, J.L. and Z.Z.

Funding: This research was funded by National Natural Science Foundation of China: No.41771198, National Natural Science Foundation of China: No. 41771576, The NSFC-NRF Scientific Cooperation Program: Grant No. 41811540400, Natural Science Basic Research Plan in Shaanxi Province of China: Program No. 2018JM4010, The Fundamental Research Funds For the Central Universities, Shaanxi Normal University: GK201901009.

Conflicts of Interest: The authors declare no conflict of interest.

\section{References}

1. Bojie, F.U.; Dandan, Y.U. Trade-off analyses and synthetic integrated method of multiple ecosystem services. Resour. Sci. 2016, 38, 5-10. [CrossRef]

2. Newton, A.; Brito, A.C.; Icely, J.D.; Derolez, V.; Clara, I.; Angus, S.; Schernewski, G.; Inácio, M.; Lillebø, A.I.; Sousa, A.I.; et al. Assessing, quantifying and valuing the ecosystem services of coastal lagoons. J. Nat. Conserv. 2018, 44, 50-65. [CrossRef]

3. Chen, L.C.; Guan, X.; Li, H.M.; Wang, Q.K.; Zhang, W.D.; Yang, Q.P.; Wang, S.L. Spatiotemporal patterns of carbon storage in forest ecosystems in Hunan province, China. For. Ecol. Manag. 2019, 432, 656-666. [CrossRef] 
4. $\quad$ Luisetti, T.; Turner, R.K.; Andrews, J.E.; Jickells, T.D.; Kröger, S.; Diesing, M.; Paltriguera, L.; Johnson, M.T.; Parker, E.R.; Bakker, D.C.E.; et al. Quantifying and valuing carbon flows and stores in coastal and shelf ecosystems in the UK. Ecosyst. Serv. 2019, 35, 67-76. [CrossRef]

5. Stritih, A.; Bebi, P.; Grêt-Regamey, A. Quantifying uncertainties in earth observation-based ecosystem service assessments. Environ. Model. Softw. 2018, 111, 300-310. [CrossRef]

6. Dai, E.; Wang, X.; Zhu, J.; Zhao, D. Methods, tools and research framework of ecosystem service trade-offs. Geogr. Res. 2016, 35, 1005-1016.

7. Xiaonan, Y.; Jing, L.; Keyu, Q.; Ting, L.; Jingya, L. Trade-offs between ecosystem services in guanzhong-tianshui economic region. Acta Geogr. Sin. 2015, 70, 1762-1773.

8. Zheng, Z.; Fu, B.; Hu, H.; Sun, G. A method to identify the variable ecosystem services relationship across time: A case study on Yanhe basin, China. Landsc. Ecol. 2014, 29, 1689-1696. [CrossRef]

9. Wang, J.; Zhai, T.; Lin, Y.; Kong, X.; He, T. Spatial imbalance and changes in supply and demand of ecosystem services in China. Sci. Total Environ. 2019, 657, 781-791. [CrossRef]

10. Petitgas, P.; Huret, M.; Dupuy, C.; Spitz, J.; Authier, M.; Baptiste Romagnan, J.; Doray, M. Ecosystem spatial structure revealed by integrated survey data. Prog. Oceanogr. 2018, 166, 189-198. [CrossRef]

11. Halouani, G.; François, L.; Shin, Y.; Velez, L.; Hattab, T.; Romdhane, M.; Lasram, F. An end-to-end model to evaluate the sensitivity of ecosystem indicators to track fishing impacts. Ecol. Indic. 2019, 98, 121-130. [CrossRef]

12. Hong, J.; Kim, J. Impact of the Asian monsoon climate on ecosystem carbon and water exchanges: A wavelet analysis and its ecosystem modeling implications. Glob. Chang. Biol. 2011, 17, 1900-1916. [CrossRef]

13. Mao, D.; Luo, L.; Wang, Z.; Wilson, M.C.; Zeng, Y.; Wu, B.; Wu, J. Conversions between natural wetlands and farmland in china: A multiscale geospatial analysis. Sci. Total Environ. 2018, 634, 550-560. [CrossRef] [PubMed]

14. Culhane, F.; Teixeira, H.; Nogueira, A.J.; Borgwardt, F.; Trauner, D.; Lillebø, A.; Piet, G.; Kuemmerlen, M.; McDonald, H.; O'Higgins, T.; et al. Risk to the supply of ecosystem services across aquatic ecosystems. Sci. Total Environ. 2018, 660, 611-621. [CrossRef] [PubMed]

15. Vörösmarty, C.J.; Osuna, V.R.; Cak, A.D.; Bhaduri, A.; Bunn, S.E.; Corsi, F.; Gastelumendi, J.; Green, P.; Harrison, I.; Lawford, R.; et al. Ecosystem-based water security and the Sustainable Development Goals (SDGs). Ecohydrol. Hydrobiol. 2018, 18, 317-333. [CrossRef]

16. Vallecillo, S.; Notte, A.L.; Zulian, G.; Ferrini, S.; Maes, J. Ecosystem services accounts: Valuing the actual flow of nature-based recreation from ecosystems to people. Ecol. Model. 2019, 392, 196-211. [CrossRef] [PubMed]

17. Villarreal, S.; Guevara, M.; Alcaraz-Segura, N.D.; Brunsell, A.B.; Hayes, D.; Loescher, H.W.; Vargas, R. Ecosystem functional diversity and the representativeness of environmental networks across the conterminous United States. Agric. For. Meteorol. 2018, 262, 423-433. [CrossRef]

18. Bernués, A.; Tello-García, E.; Rodríguez-Ortega, T.; Ripoll-Bosch, R.; Casasús, I. Agricultural practices, ecosystem services and sustainability in high nature value farmland: Unraveling the perceptions of farmers and nonfarmers. Land Use Policy 2016, 59, 130-142. [CrossRef]

19. Weitzman, J. Applying the ecosystem services concept to aquaculture: A review of approaches, definitions, and uses. Ecosyst. Serv. 2019, 35, 194-206. [CrossRef]

20. Smith, R.I.; Barton, D.N.; Dick, J.; Haines-Young, R.; Madsen, A.L.; Rusch, G.M.; Termansen, M.; Woods, H.; Carvalho, L.; Giucă, R.C.; et al. Operationalising ecosystem service assessment in Bayesian Belief Networks: Experiences within the OpenNESS project. Ecosyst. Serv. 2018, 29, 452-464. [CrossRef]

21. Hooper, T.; Beaumont, N.; Griffiths, C.; Langmead, O.; Somerfield, P.J. Assessing the sensitivity of ecosystem services to changing pressures. Ecosyst. Serv. 2017, 24, 160-169. [CrossRef]

22. Firbank, L.; Bradbury, R.B.; Mccracken, D.I.; Stoate, C. Delivering multiple ecosystem services from enclosed farmland in the UK. Agric. Ecosyst. Environ. 2013, 166, 65-75. [CrossRef]

23. Leung, X.Y.; Xue, L.; Wen, H. Framing the sharing economy: Toward a sustainable ecosystem. Tour. Manag. 2019, 71, 44-53. [CrossRef]

24. Danilo, R.; Luciano, B.; Leonardo, A. Novel perspectives on bat insectivory highlight the value of this ecosystem service in farmland: Research frontiers and management implications. Agric. Ecosyst. Environ. 2018, 266, 31-38. 
25. Fox, W.E.; Medina-Cetina, Z.; Angerer, J.; Varela, P.; Ji, R.C. Water quality \& natural resource management on military training lands in central Texas: Improved decision support via Bayesian networks. Sustain. Water Q. Ecol. 2017, 9-10, 39-52.

26. Landuyt, D.; Lemmens, P.; D’hondt, R.; Broekx, S.; Liekens, I.; De Bie, T.; Declerck, S.A.; De Meester, L.; Goethals, P.L. An ecosystem service approach to support integrated pond management: A case study using Bayesian belief networks-Highlighting opportunities and risks. J. Environ. Manag. 2014, 145, $79-87$. [CrossRef] [PubMed]

27. Macpherson, M.P.; Webb, E.B.; Andrew, R.; Doreen, M.; Frank, N. A review of Bayesian belief network models as decision-support tools for wetland conservation: Are water birds potential umbrella taxa. Biol. Conserv. 2018, 226, 215-223. [CrossRef]

28. Sperotto, A.; Molina, JL.; Torresan, S.; Critto, A.; Marcomini, A. Reviewing Bayesian networks potentials for climate change impacts assessment and management: A multi-risk perspective. J. Environ. Manag. 2017, 202, 320-331. [CrossRef] [PubMed]

29. Jung, M.C.; Park, J.; Kim, S. Spatial Relationships between Urban Structures and Air Pollution in Korea. Sustainability 2019, 11, 476. [CrossRef]

30. Wu, J.; Hu, Z.; Chen, J.; Li, Z. Risk Assessment of Underground Subway Stations to Fire Disasters Using Bayesian Network. Sustainability 2018, 10, 3810. [CrossRef]

31. Pérez-Sánchez, J.; Senent-Aparicio, J.; Segura-Méndez, F.; Pulido-Velazquez, D.; Srinivasan, R. Evaluating Hydrological Models for Deriving Water Resources in Peninsular Spain. Sustainability 2019, 11, 2872. [CrossRef]

32. Kleemann, J.; Celio, E.; Nyarko, B.K.; Jimenez-Martinez, M.; Fürst, C. Assessing the risk of seasonal food insecurity with an expert-based Bayesian Belief Network approach in northern Ghana, West Africa. Ecol. Complex. 2017, 32, 53-73. [CrossRef]

33. Pascual, M.; Miñana, E.P.; Giacomello, E. Integrating knowledge on biodiversity and ecosystem services: Mind-mapping and Bayesian Network modelling. Ecosyst. Serv. 2016, 17, 112-122. [CrossRef]

34. Pedreschi, D.; Bouch, P.; Moriarty, M.; Nixon, E.; Knights, A.M.; Reid, D.G. Integrated ecosystem analysis in Irish waters; Providing the context for ecosystem-based fisheries management. Fish. Res. 2019, 209, 218-229. [CrossRef]

35. Knoke, T.; Paul, C.; Hildebrandt, P.; Calvas, B.; Castro, L.M.; Härtl, F.; Döllerer, M.; Hamer, U.; Windhorst, D.; Wiersma, Y.F.; et al. Compositional diversity of rehabilitated tropical lands supports multiple ecosystem services and buffers uncertainties. Nat. Commun. 2016, 7, 11877. [CrossRef]

36. Mcdonald, K.S.; Ryder, D.S.; Tighe, M. Developing best-practice bayesian belief networks in ecological risk assessments for freshwater and estuarine ecosystems: A quantitative review. J. Environ. Manag. 2015, 154, 190-200. [CrossRef]

37. Mcdonald, K.S.; Tighe, M.; Ryder, D.S. An ecological risk assessment for managing and predicting trophic shifts in estuarine ecosystems using a bayesian network. Environ. Model. Softw. 2016, 85, 202-216. [CrossRef]

38. Dlamini, W.M. A bayesian belief network analysis of factors influencing wildfire occurrence in Swaziland. Environ. Model. Softw. 2010, 25, 199-208. [CrossRef]

39. Dal Ferro, N.; Quinn, C.; Morari, F. A bayesian belief network framework to predict soc dynamics of alternative management scenarios. Soil Tillage Res. 2018, 179, 114-124. [CrossRef]

40. Landuyt, D.; Broekx, S.; D'Hondt, R.; Engelen, G.; Aertsens, J.; Goethals, P.L.M. A review of bayesian belief networks in ecosystem service modelling. Environ. Model. Softw. 2013, 46,1-11. [CrossRef]

41. Shaw, E.; Kumar, V.; Lange, E.; Lerner, D.N. Exploring the utility of bayesian networks for modelling cultural ecosystem services: A canoeing case study. Sci. Total Environ. 2016, 540, 71-78. [CrossRef]

42. Gonzalezredin, J.; Luque, S.; Poggio, L.; Smith, R.; Gimona, A. Spatial bayesian belief networks as a planning decision tool for mapping ecosystem services trade-offs on forested landscapes. Environ. Res. 2016, 144, 15-26. [CrossRef]

43. Nourikhah, H.; Akbari, M.K. Impact of service quality on user satisfaction: Modeling and estimating distribution of quality of experience using Bayesian data analysis. Electron. Commer. Res. Appl. 2016, 17, 112-122. [CrossRef] 
44. Li, Z.; Jing, L.I.; Ting, L.I.; Xiaonan, Y.; Yanze, W. Optimizing spatial patterns of water conservation ecosystem service based on bayesian belief networks. Acta Geogr. Sin. 2018, 73, 1809-1822.

45. Shuohao, L.I.; Jun, Z. Review of Bayesian networks structure learning. Appl. Res. Comput. 2015, 32, 641-646.

46. Chen, C.; Xie, G.; Zhen, L.; Leng, Y. Analysis on Jinghe River watershed vegetation dynamics and evaluation on its relation with precipitation. Acta Ecol. Sin. 2008, 28, 925-938.

47. Xie, G.; Zhen, L.; Chen, C.; Yang, L. The Changes and Their Interactions of Precipitation-Landscape-Runoff in Jinghe Watershed. Resour. Sci. 2007, 29, 156-163.

48. Guo, A.; Chang, J.; Wang, Y.; Li, Y. Variation characteristics of rainfall-runoff relationship and driving factors analysis in Jinghe river basis in nearly 50years. Trans. Chin. Soc. Agric. Eng. 2015, 31, 165-171.

49. Li, J.; Gao, J.; Zhang, Y.; Shao, H. Effects of Terrace on Runoff and Ecological Base Flow of Jinghe Watershed in Loess Plateau Region. Bull. Soil Water Conserv. 2015, 35, 106-110,116.

50. Ning, T.; Li, Z.; Li, W. Separating the impacts of Climate change and Land surface alteration on runoff reduction in the Jing River catchment of China. Catena 2016, 147, 80-86. [CrossRef]

51. Peng, H.; Jia, Y.; Niu, C.; Gang, J.; Hao, C.; Gou, S. Eco-hydrological simulaton of soil and water conversation in the Jinghe River Basin in the Loess Platea, China. J. Hydro-Environ. Res. 2015, 9, 452-464. [CrossRef]

52. Suo, A.; Yu, B.; Wang, H.; Ge, J. Regulation of Vegetation Landscape Pattern on Runoff in Watershed of Loess Plateau. J. Soil Water Conserv. 2005, 19, 40-43.

53. Yang, L.; Zhen, L.; Xie, G.; Chen, C. Effects on Changing Grain Size of Landscape Indices in Jinghe Watershed. Resour. Sci. 2007, 29, 183-187.

54. Zhen, L.; Xie, G.; Yang, L.; Cheng, S. Challenges Facing Landscape Management in the Jinghe Watershed of Northwest China by Using Participatory Rual Apprisal. China Popul. Resour. Environ. 2007, 17, 129-133.

55. Pan, Y.; Zhen, L.; Long, X.; Can, X. Ecosystem service interactions and their affecting factors in Jinghe watershed at county level. Chin. J. Appl. Ecol. 2012, 23, 1203-1209.

56. Suo, A.; Xiong, Y.; Wang, T.; Yue, D.; Ge, J. Ecosystem Health Assessment of the Jinghe River Watershed on the Huangtu Plateau. EcoHealth 2008, 5, 127-136. [CrossRef]

57. Chen, D.; Li, J.; Zhou, Z.; Liu, Y.; Li, T.; Liu, J. Simulating and mapping the spatial and seasonal effects of future climate and land-use changes on ecosystem services in the Yanhe watershed, China. Environ. Sci. Pollut. Res. 2017, 25, 1115-1131. [CrossRef]

58. Zhu, W.; Pang, Y.; Zhang, J. Estimation Of Net Primary Productivity of Chinese Terrestrial Vegetation Based On Remote Sensing. Chin. J. Plant Ecol. 2007, 31, 413-424.

59. Wu, B.F.; Xiong, J.; Yan, N.N.; Yang, L.D.; Du, X. Etwatch for monitoring regional evapotranspiration with remote sensing. Adv. Water Sci. 2008, 19, 671-678.

60. Wischmeier, W.H.; Smith, D.D. Rainfall energy and its relationship to soil loss. Trans. Am. Geophys. Union 1958, 39, 285-291. [CrossRef]

61. Bian, H.; Pang, J.; Ren, Z.; Xu, Q. Effects of land use change on soil conservation value in southern Loess Plateau of Northwest China. Chin. J. Ecol. 2012, 31, 2391-2396.

62. McCool, D.K.; Foster, G.R.; Mutchler, C.K.; Meyer, L.D. Revised Slope Length Factor for the Universal Soil Loss Equation. Trans. ASAE 1989, 32, 1571-1576. [CrossRef]

63. Guo, Q.; Liu, B.; Zhu, S.; Wang, G.; Liu, Y.; Wang, A. Main Farming Measures for Soil and Water Conservation in China. Soil Water Conserv. China 2013, 10, 22-26.

64. Su, Y.; Song, S.; Sun, S. Calculation Method for USLE Equation Factors Based on GIS. Xiandai Nongye Keji 2013, 1, 206-207, 209.

65. Franco, C.; Hepburn, L.A.; Smith, D.J.; Nimrod, S.; Tucker, A. A bayesian belief network to assess rate of changes in coral reef ecosystems. Environ. Model. Softw. 2016, 80, 132-142. [CrossRef]

66. Dang, K.B.; Windhorst, W.; Burkhard, B.; Müller, F. A bayesian belief network-based approach to link ecosystem functions with rice provisioning ecosystem services. Ecol. Indic. 2018, 100, 30-44. [CrossRef]

67. Forio, M.A.; Landuyt, D.; Bennetsen, E.; Lock, K.; Nguyen, T.H.; Ambarita, M.N.; Musonge, P.L.; Boets, P.; Everaert, G.; Dominguez-Granda, L.; et al. Bayesian belief network models to analyse and predict ecological water quality in rivers. Ecol. Model. 2015, 312, 222-238. [CrossRef] 
68. Chee, Y.E.; Wilkinson, L.; Nicholson, A.E.; Quintana-Ascencio, P.F.; Fauth, J.E.; Hall, D.; Ponzio, K.J.; Rumpff, L. Modelling spatial and temporal changes with gis and spatial and dynamic bayesian networks. Environ. Model. Softw. 2016, 82, 108-120. [CrossRef]

69. Tian, Y.; Wang, S.; Bai, X.; Luo, G.; Xu, Y. Trade-offs among ecosystem services in a typical karst watershed, SW china. Sci. Total Environ. 2016, 566-567, 1297-1308. [CrossRef] 